\title{
تصور مقترح لجودة الأداء الوظيفي لدى مديري الاندية الرياضية بمحافظة الوادي الجديد في ضوء بعض المتفيرات التنظيمية
}

عماد فتحى عبد اللطيف

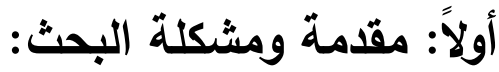

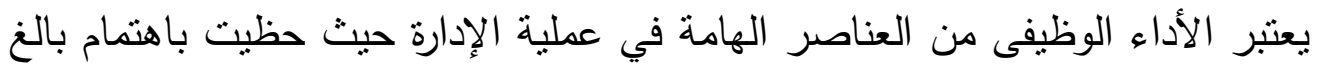
وشهد دراسات مستمرة عن حلول للمشكلات المتعلقة به، إذ أنه يعتبر الوسيلة الوحيدة

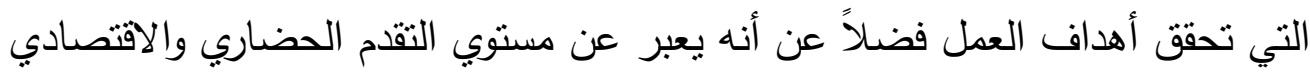

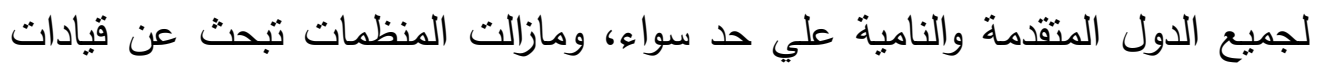

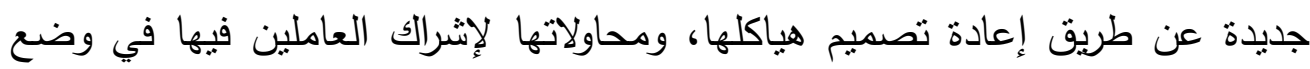

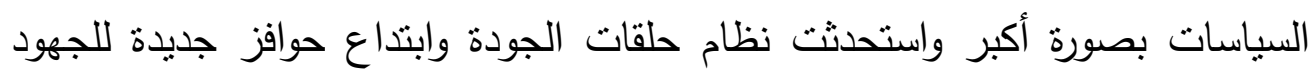

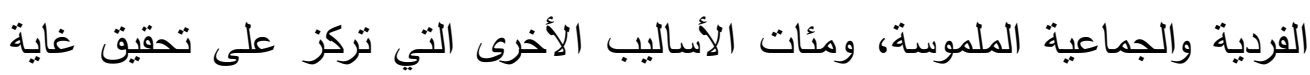

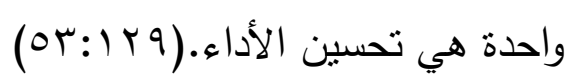

فالأداء الوظيفى هو قدرة الإدارة علي تحويل الدخخلات الخاصة بالتتظيم إلي عدد من

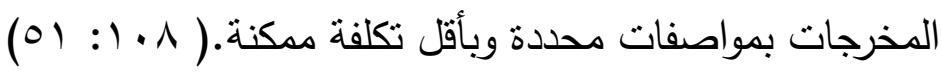

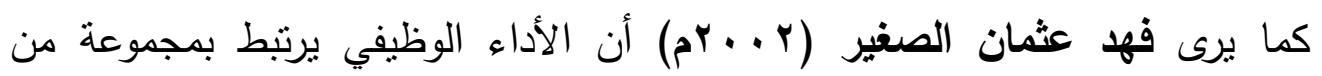

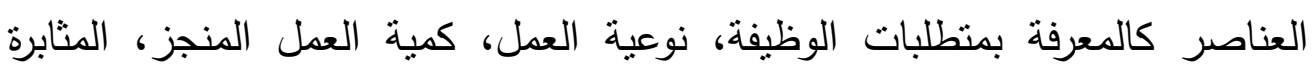

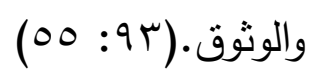

وتأنى الجودة لنتمل أحد العناصر الأساسية لتحقيق هذه الميزة التتافسية ذات البعد

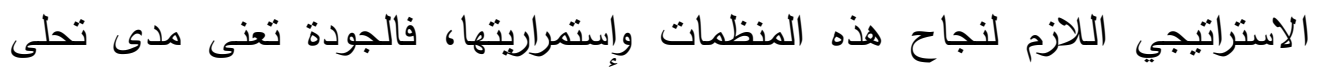

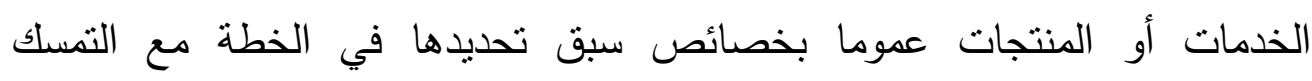

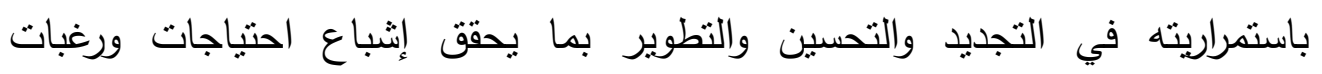

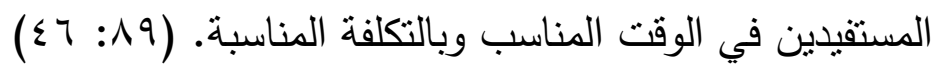


وترتبط جودة الأداء الوظيفي بالانجاز الذي يحققه الفرد من خلال تعظيم كمية وجودة

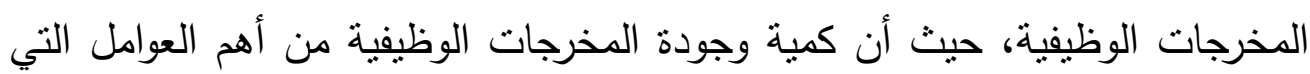
يجب أخذها في الاعتبار عند تقييم الأداء الوظيفي للفرد واتخاذ القرارات المترتبة على اهن اهن

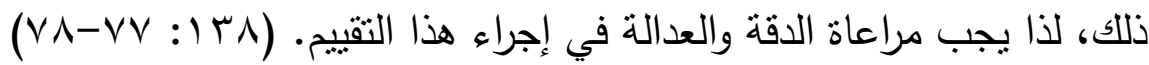
وتتضمن جودة الأداء الوظيفي الإبداع أو الابتكار في أداء الوظيفة، والإلمام بكل جوانب الوظيفة، والالتزام الوظيفي من حيث المواعيد، والدقة في أداء الوظيفة، وتوافر القدرة على أداء الوظيفة، وحسن إصدار الإحكام أو القرارات الوظيفية. (10. (1) (10V-107

ويذكر صالح مهاي العامري، الغالبي محسن، طاهر محسن منصور (11 + ب م) أن من أهم العوامل الرئيسية لنجاح أي منظمة وزيادة فاعليتها هو وجود الطاقات الإبداعية

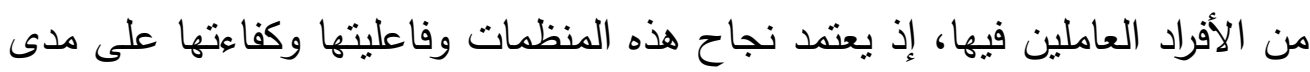
إستعداد هؤلاء الأفراد للعمل بكفاءة ودقة وإتقان من أجل نجاح هذا التتظيم، ولهذا فإن

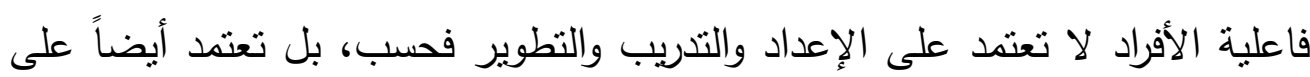
درجة ومستوى ولائهم ورضاهم عن التنظيمات التي يعملون فيها (YT: Y Y I I) وتعتبر المتغيرات التتظيمية بمثابة مجموعة من العوامل ذات التأثير المنبادل والتي تجعل المؤسسة تختلف باختلافها وتتأثز في ترتيب واجباتها التي تستخدم من أجل تتظيم أعمالها، والتي ينبخي إنجازها مع الأخذ في الإعتبار مجموعة الخصائص التي لتي

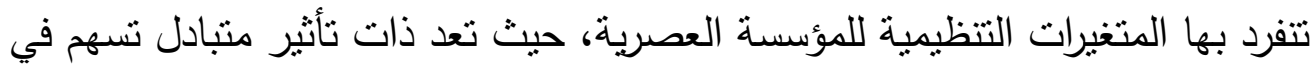
جعل المؤسسة تختلف بإختلافها وفي ظل هذا الإختلاف يمكن تتاول هذه المتغيرات في إطار عصري ينعكس إيجابا على أداء العاملين بأي مؤسسة.

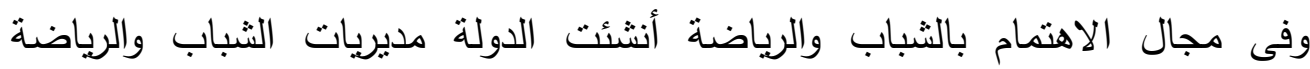
بمختلف محافظات الجمهورية ضمن الهيكل التتظيمي لرعاية الثباب والرياضة والذي باتي يمثله حاليا "المجلس القومي للثباب والمجلس القومي للرياضة " التي تم إنشاؤها بقرار

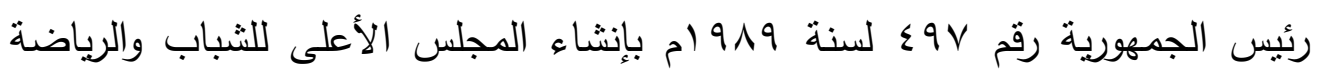


كهيئة عامة تهدف إلى توفير فرص النمو المتكامل والارتقاء بالمستوى المطلوب للنشء والثباب عن طريق الأنشطة الرياضية. (9 (19: (19)

وتعتبر الاندية الرياضيةهن المؤسسات الاجتماعية والتي تهنم بإعداد الثباب، إعدادًا ثقافيًا وقيميًا واجتماعيًا وبدنيًا ونفسيًا من خلال البرامج والأنشطة التي يقدمها الاندية الرياضيةالمنتشرة في كل المحافظات والمدن والقرى وذللك من خلال مشرفين ومتخصصين في كافة البرامج والأنشطة المتعددة المقدمة للثباب. ويقصد بمؤسسات الاندية الرياضيةبأنها مؤسسات يتجمع فيها الثباب لممارسة الأنشطة المختلفة في سهولة ويسر وارتقاء إلى مستوى المواطنة الصالحة دون تحديد أو تخصيص لنوع معين أو فئة من المواطنين، ولكنها مدرسة شعبية وطنية تمارس فيها شتى الهوايات والألعاب والفنون وبعض المشروعات والبرامج التي تخص البيئة

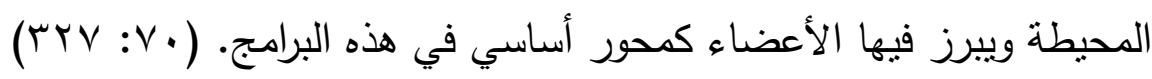
وتعرف الاندية الرياضيةعلى أنها مؤسسات تعمل لخدمة الثباب وتهيأ لهم فرص فه لهره استثمار وقت فراغهم في أنشطة رياضية وثقافية واجتماعية لإشباع حاجاتهم وتتمية

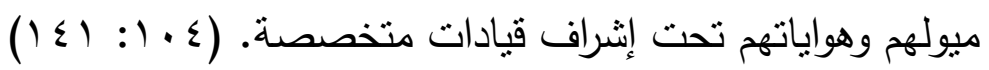
كما تعرف الاندية الرياضيةأيضًا بأنها كل هيئة مجهزة بالمباني والإمكانيات تقيمها الدولة أو المجالس المحلية أو الأفراد في المدن والقرى بقصد تتمية الثباب في مراحل العمر المختلفة واستثمار أوقات فراغه في ممارسة الأنشطة الترويحية والاجنماعية

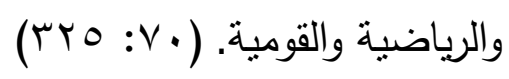

ومن خلا إجراء الباحث بعض المقابلات "غير المقننة " ببعض مديري الاندية الرياضيةلاحظ الباحث أن جودة الأداء الوظيفي تكاد تكون منعدمة حيث أن المديرين

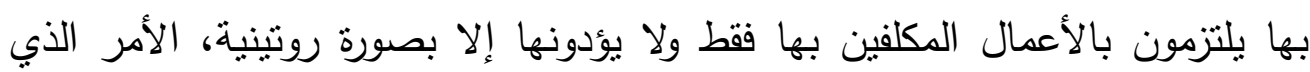
يرجعه الباحث إلي افتقاد المديرين للشعور بأهمية دورهم في إنجاح المنظمة التي

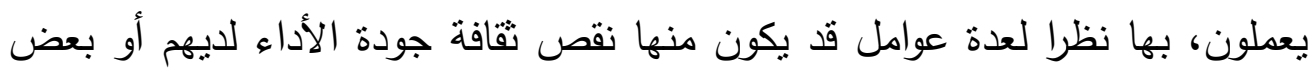
العوامل الأخرى التي قد تكون مرتبطة بالمتغيرات التنظيمية للأداء الوظيفي الجيد والتي لهي 
تشجع المديرين على التغلب علي المشكلات التي قد تواجهه أثناء العمل مما يؤدي إلى ضعف مستوبي الإنجاز والقضاء علي الثكل الروتيني في العمل، فعلى الرغم من أنه لايعتبر أداء رسمياً بحد ذاته إلا أنه يسمح ويساهم في تحقيق الأهداف الكلية للمنظمة وإذا تم استغلاله الاستغلال الأمنل بؤدي بدوره إلى زيادة فاعلية وجودة الأداء الوظيفي.

مما سبق يتضح -على حد علم الباحث - أنه إذا أريد لأي منظمة النجاح فلا بد أن تتظر بعين الإعتبار للأداء الوظيفي على أنه احد محاور بل أهم محاور جودة

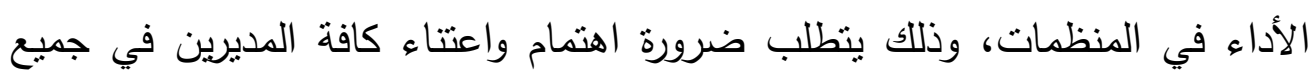
المستويات التتظيمية بنطوير وتتمية أداء المرؤوسين من حيث الكمية والجودة حيث ينعكس ذلك على أداء جماعات العمل والنتيجة أو المحصلة النهائية وهي فاعلية أداء المنظمة، وهذا يتطلب معه دراسة أكثر المتغيرات التتظيمية التي تؤثز وتساهم في الوصول بالأداء الوظيفي إلى الجودة المطلوبة. وهذا ما دفع الباحث للقيام بنلك الدراسة كمحاولة لوضع تصور مقترح لجودة الأداء الوظيفي لدى مديري الاندية الرياضيةبمحافظة الوادي الجديد في ضوء بعض المتغيرات التظظيمية.

\section{ثانياً: هدف البحث:}

يهدف البحث إلى وضع تصور مقترح لجودة الأداء الوظيفي لمديري الاندية الرياضيةبمحافظة الوادي الجديد في ضوء بعض المتغيرات التتظيمية، من خلال الاجابة عن التساؤلات التالية: 1- ما المتغيرات التنظيمية المتوفرة بالاندية الرياضيةبمحافظة الوادي الجديد؟ r- ما مستوى جودة الأداء الوظيفي لدى مديري الاندية الرياضيةبمحافظة الوادي الجديد؟ 
r- هل توجد علاقة دالة إحصائية بين المتغيرات التنظيمية (قيد البحث) وجودة

$$
\text { الأداء الوظيفي لدى مديري مراكز الثباب؟ }
$$

ع - ما نسبة مساهمة المتغيرات التتظيمية على جودة الأداء الوظيفي لدى مديري

$$
\text { الاندية الرياضيةبمحافظة الوادي الجديد؟ }
$$

ه- ما التصور المقترح لجودة الأداء الوظيفي لدى مديري الاندية الرياضينبمحافظة

الوادي الجديد في ضوء بعض المتغيرات التنظيمية؟

$$
\text { - ثالثًاً: خطة وإجراءات البحث: }
$$

استخدم الباحث المنهج الوصفي وذلك لمناسبته لطبيعة البحث.

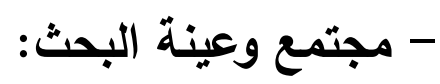

يشمل مجتمع البحث على مديري الاندية الرياضيةبمحافظة الوادي الجديد، تم اختيار

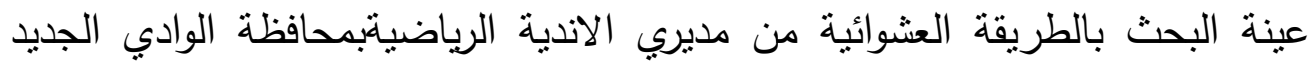

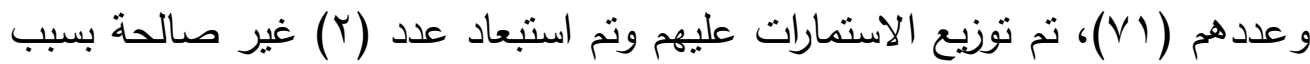
عدم دقة الاستجابات، وبذلك بلغ عدد العينة (79) مدير، كما تم اختيار عينة

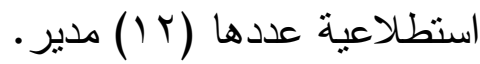

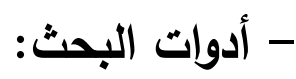

أ- استمارة استبيان الواقع الفعلي لجودة الأداء الوظيفي لرحاب سيد مبروك $: p r+1 Y$ استخدم الباحث استمارة استبيان الواقع الفعلي لجودة الأداء الوظيفي لرحاب سيد مبروك r I • r ويتألف من (T7) فقرة موزعة على ع محاور وهذه المحاور هي: (جوانب الجودة داخل المؤسسات الرياضية، رضا العاملين عن الوظيفة، تقييم الأداء داخل المؤسسات الرياضية، حسن إصدار الإحكام والقرارات الوظيفية). 
تعطى درجة وفقاً لميزان التقدير الثلاثي (موافق، محايد، غير موافق) على الترتيب (0،

استخدم الباحث صدق الاتساق الداخلى لحساب معامل الصدق للاستبيان (بين العبارات ومجموع المحور المنتمية إليه، وأيضاً بين المحاور والمجموع الكلى للاستمارة) وذللك بهدف التحقق من صدق استمارة الاسنبيان، حيث تم تطبيق الاستبيان على مجموعة قوامها (0 (1) فرد من مجتمع البحث ومن خارج عينة البحث الأساسية. وأتضح أن معاملات الارتباط بين عبارات المحور الأول والمجموع الكلي للمحور تراوحت ما بين (VT. . : 90. .)، كما أتضح أن معاملات الارتباط بين عبارات

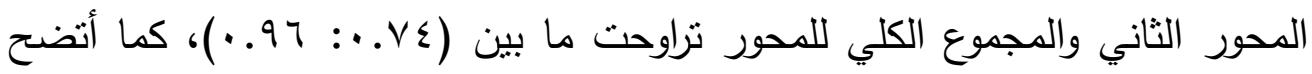

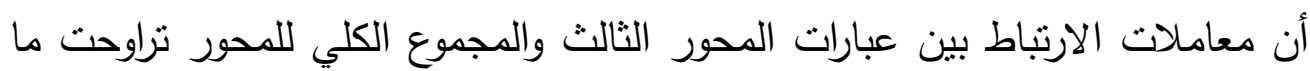

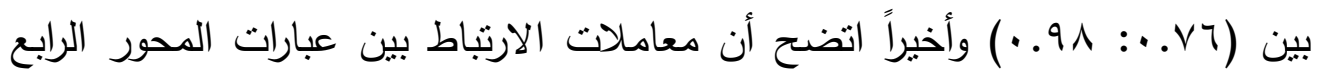

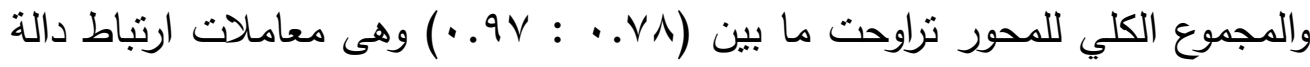
إحصائياً عند مستوى (0 . . ) مما يشير إلى الاتساق الداخلى للمحاور الأربعة. بينما أتضح أن معاملات الارتباط بين مجموع كل محور والمجموع الكلي للمحور

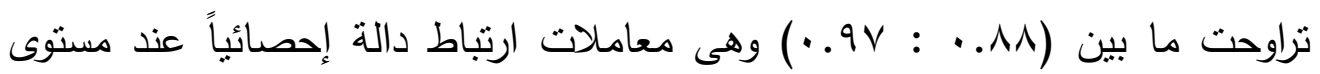
(0.0. . ) مما يشير إلى الاتساق الداخلى للاستمارة ككل. ولإيجاد معامل الثبات استخدم الباحث طريقة التطبيق وإعادة التطبيق على عينة قوامها (Y) (Y)، والسابق استخدامها في إيجاد الصدق وبفارق زمني قدرة (0) يوماً، وأتضح وجود علاقة إيجابية ودالة إحصائياً بين التطبيقين الأول والثاني بمختلف

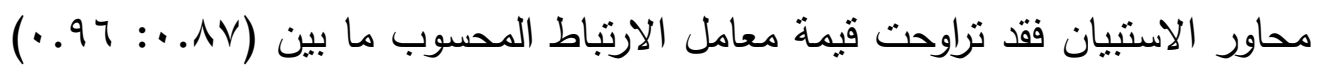
وهي أعلى من قيمتها الجدولية عند مستوى ه. .. مما يشير إلى ثبات الاستبيان. وبذلك أصبح جاهز للتطبيق. ب- استبيان المتغيرات التنظيمية: اعداد الباحث 
بعد الإطلاع على الدراسات المرجعية قام الباحث بإعداد استمارة استطلاع رأى الخبراء حول محاور الاستمارة لإبداء الرأي في مدى مناسبتها لموضوع البحث، وتم عرضها على مجموعة من الخبراء في مجال الإدارة الرياضية وعددهم (9) وذللك لإبداء الرأي في مدى مناسبة المحاور من عدمه، وأتضح أن النسبة المئوية لأراء السادة الخبراء

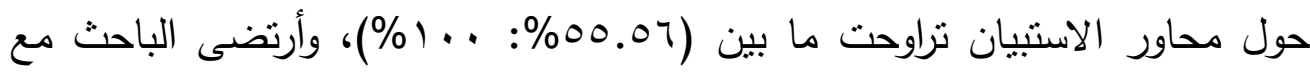
هيئة الإشراف قبول نسبة • v\% فأكثر من آراء السادة الخبراء وبذلك تم التوصل إلى الى المحاور النهائية للاستبيان وعددها ه محاور وهي على الترتيب (التقافة التنظيمية، الابداع الإداري، الاتصال الإداري، الإدارة الإلكترونية، الهيكل التظيمي).

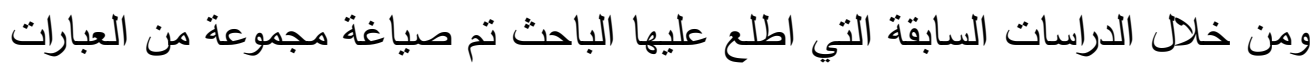
التي يحاول عن طريقها كثف الغموض حول التساؤلات موضوع الدراسة، وكذلك تحديد الثكل العام للاسنبيان ، وقد راعى الباحث عند صياغة عبارات الإستبيان أن تكون العبارات سهلة وبسيطة ومفهومه وقد بلغ عدد عبارات الإستبيان في صورته

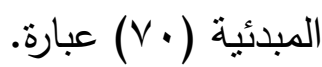

ثم قام الباحث بعرض تلك العبارات على مجموعة من السادة الخبراء في مجال علم النفس الرياضي قوامها (9) خبراء وذللك للتعرف على مدى صلاحية العبارات، وأتضح أن النسبة المئوية لاراء السادة الخبراء في العبارات المقترحة للمحور الأول النقافة التتظيمية لاستبيان المتغيرات التتظيمية لاى مديري الاندية الرياضيةبمحافظة الوادي الجديد تراوحت ما بين (00.07\%، . . (1\%)، وأرتضى الباحث مع هيئة الإشراف قبول نسبة • v\% فأكثر من آراء السادة الخبراء وبذللك تم حذف العبارة (9). وللمحور

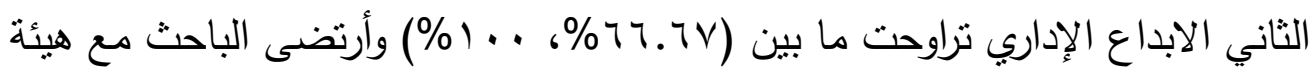
الإشراف قبول نسبة •v\% فأكثر من آراء السادة الخبراء وبذلك نم حذف العبارتين

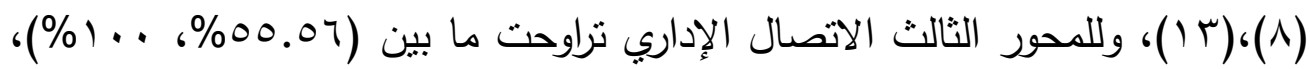
وأرتضى الباحث مع هيئة الإشراف قبول نسبة • \& فأكثر من آراء السادة الخبراء وبذلك تم التوصل إلى تعديل صياغة بعض العبارات وكذلك استبعاد (r) عبارات وهم 


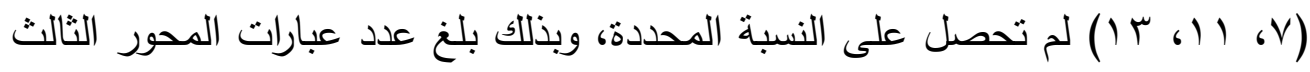

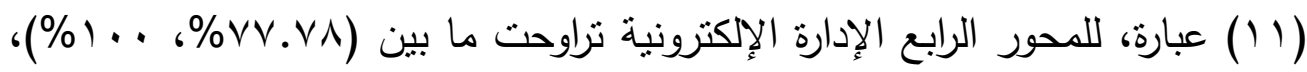
وأرتضى الباحث مع هيئة الإشراف قبول نسبة • \& فأكثر من آراء السادة الخبراء وعلى ذلك تم قبول جميع العبارات، وبلغ عدد عبارات المحور الرابع (10) عبارة،

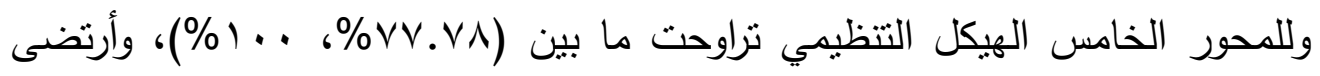
الباحث مع هيئة الإشراف قبول نسبة . v\% فأكثر من آراء السادة الخبراء وبذللك تم قبول جميع العبارات، وبلغ عدد عبارات المحور الخامس (• ( ) عبارات. وإستخدم الباحث صدق الإتساق الداخلي لحساب معامل الصدق وذلك بهدف التحقق من صدق إستمارة الإستبيان، حيث نم تطبيق الإستبيان على مجموعة قوامها (Y)

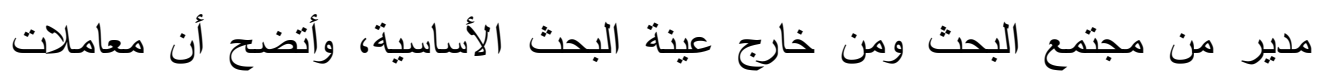

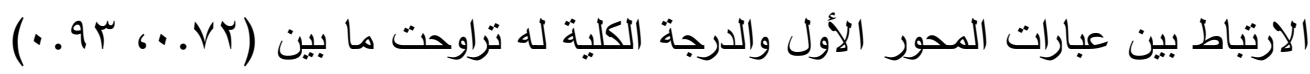

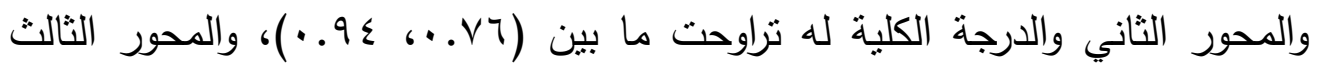

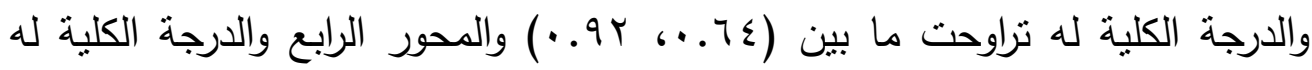

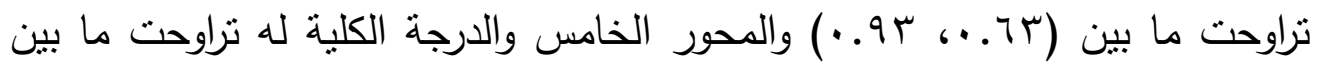

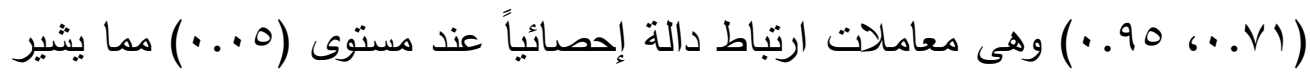
إلى الاتساق الداخلى للمحاور الخمسة. كما يتضح أن معاملات الارتباط بين مجموع كل محور والدرجة الكلية للاستمارة

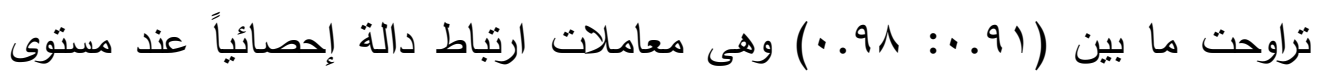
(0.0. • ) مما يشير إلى الاتساق الداخلى للاستمارة ككل. واستخدم الباحث طريقة الإختبار وإعادة الإختبار لحساب معامل الثبات لإستمارة

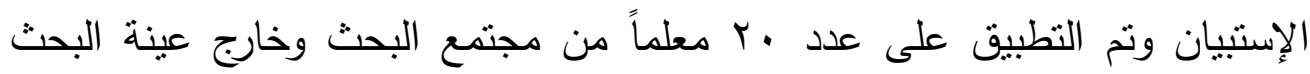
الأساسية وإعادة التطبيق على نفس المجموعة من الأفراد بعد فنرة زمنية أسبوعين ثقريباً وتحت ظروف موحدة وأتضح أن معاملات الارتباط بين التطبيق الأول والتطبيق الثاني 
تراوحت ما بين (A9. ..: 9V. . ) وهى معاملات ارتباط دالة إحصائياً عند مستوى (0. . . ) مما يشير إلى ثبات الاستمارة، وبذلك يصبح الإستبيان قابل للنطبيق. رابعاً: الاراسة الاستطلاعية: قام الباحث بإجراء دراسة استطلاعية على عينة عثوائية مكونة من (Y I) مديرا من مجتمع البحث ومن خارج عينة البحث وذللك بهدف التعرف على مناسبة العبارات لمستوى فهم العينة، التأكد من عدم وجود أي عبارات يصعب فهمها، تحديد زمن إنه الإجابة عن الإستبيان، إيجاد صدق وثبات الإسنبيان. وقد أظهرت نتائج الدراسة الإستطلاعية أن العبارات مناسبة من حيث الصبية الصياغة واللغنة المستخدمة ولم تظهر أي تعليقات توحي بالصعوبة أو عدم الفهم. ولقد قام الباحث بشرح الهدف من البحث وأهمية الاستجابة لما تحمله استمارة الاستبيان بداخلها، حتى ونى باته يمكن الاعتماد على النتائج المستخرجة فيما بعد. خامساً: تطبيق أدوات البحث:

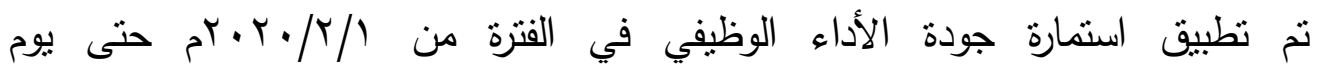
$\cdot r^{0} \cdot T \cdot / T / Y T$

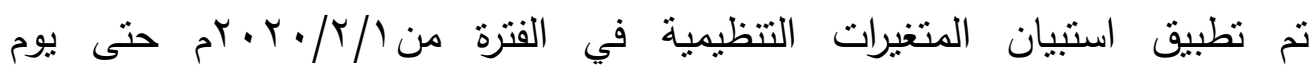

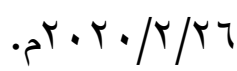
سادساً: عرض النتائج ومناقشتها وتفسيرها تحقيقاً لأهداف البحث ووصولاً للإجابة على تساؤلاته وفي حدود ما توصل إليه الباحث من بيانات من خلال التحليل الإحصائي يحاول الباحث عرض النتائج وتفسيرها ومناقشتها، وسوف يتم سردها وفقاً لتساؤلات للبحث كما يلي:

نتائج التساؤل الأول: ما المتغيرات التظيمية المتوفرة بالاندية الرياضيةبمحافظة الوادي الجديد؟ أن النسبة المئوية لفقرات المحور الأول التقافة التتظيمية لاستبيان المتغيرات التتظيمية

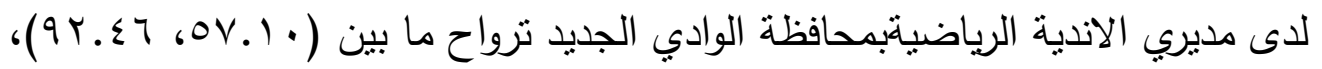




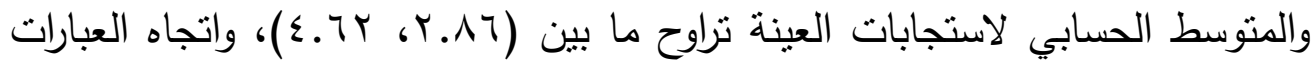

$$
\text { تؤاوح من (منتوسط: قوي). }
$$

كما يتضح أن أعلى نسبة مئوية لاستجابة عينة البحث كانت المفردة "تتطابق أعمال مجلس الادارة مع قراراته في العمل داخل مراكز الثباب"، والمفردة "تمثل المصارحة لإنه والاتصالات المفتوحة بين مجلس الإدارة والفئات المختلفة العاملة بالاندية

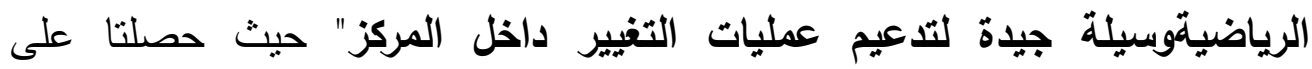

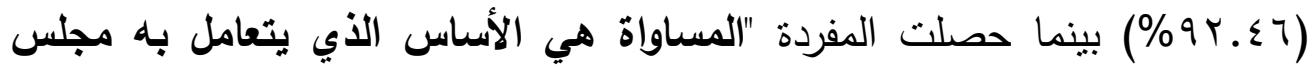

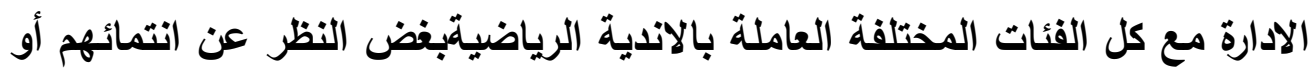

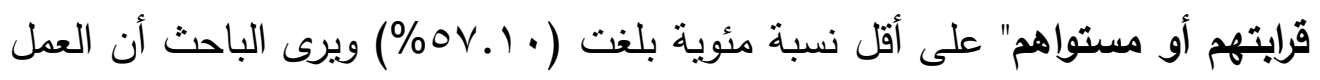

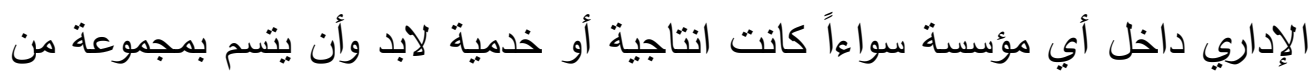

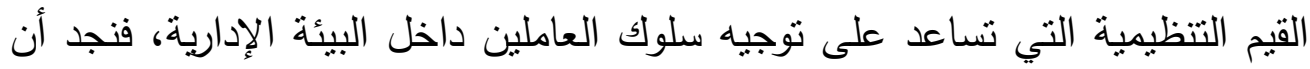
الثفافية والمصارحة قد حققت أعلى نسبة مئوية دليلاً على أن المنظمومه الإدارية

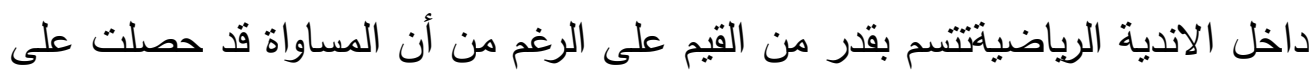

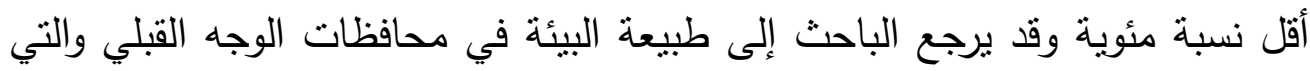
تتسم بالقبلية والعصبية ونظام العائلات.

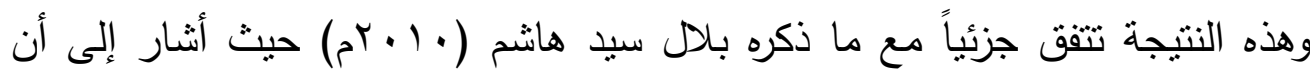
القيم التتظيمية تمثل القيم في مكان أو بيئة العمل، بحيث تعمل هذه القيم على توجيه سلوك العاملين ضمن الظروف التتظيمية المختلفة، ومن هذه القيم المساواة بين العاملين، والاهتمام بإدارة الوقت، الاهتمام بالأداء واحترام الآخربن. (ع ب: Y I )

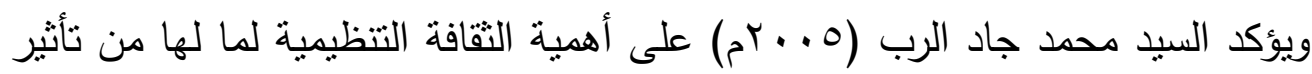

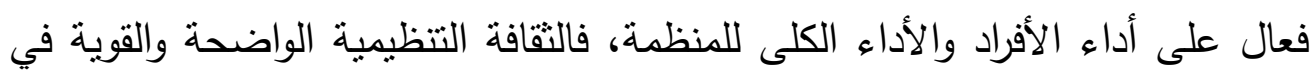

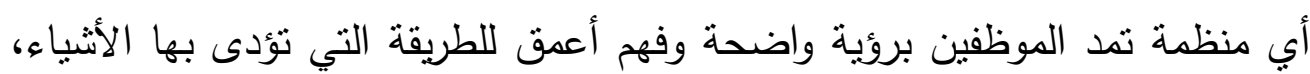

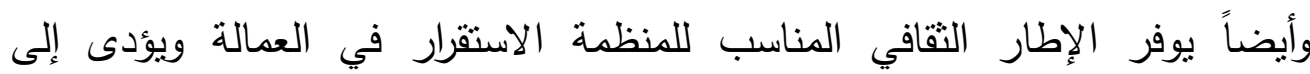
انخفاض معدل دوران العمل، ووجود إستجابة سريعة لقرارات الإدارة العليا.(1) 
أن الوزن النسبي لفقرات المحور الثاني الإبداع الإداري لاستبيان المتغيرات التتظيمية

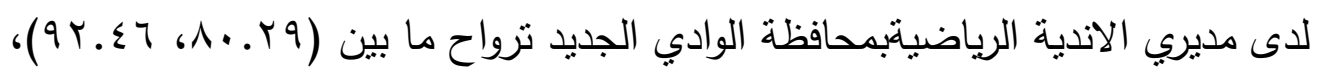

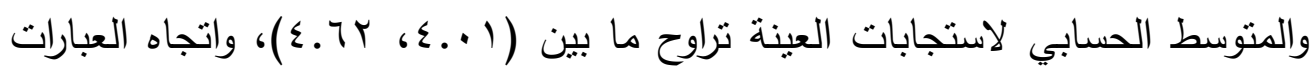
قوي. كما يتضح أن أعلى نسبة مئوية لاستجابة عينة البحث كانت المفردة " أتمتع بثقة عالية تمكنتي من مواجهة المشكلات التي تواجهني بحزم"، حيث حصلت على لابلى الته

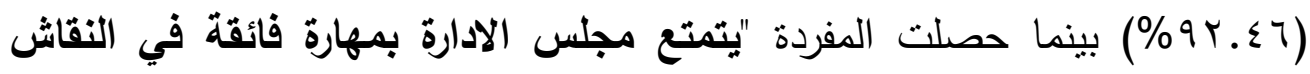

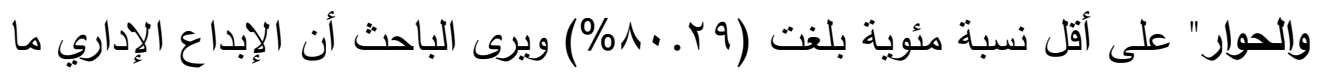
هو إلا حل لمشكلة والعمل الإداري داخل أي منظمة يقوم على سياسات مواجهة المشكلات والعمل على حلها واتخاذ قرارات هامة بشأنها.

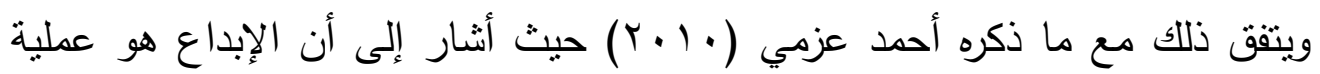
الإحساس بالمشكلات أو الثغرات في المعلومات، وصياغة الأفكار أو الفروض واختئار الإبار وتعديل هذه الفروض، وإيصال النتائج، وهذه العملية تقود إلى العديد من الانتاجات

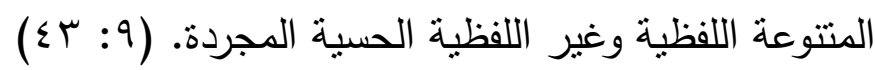
ومن خلا النتائج السابقة نرى أن هنالك مهارات لاى مديري الاندية الرياضيةقد نؤثر على عملية الإبداع الإداري داخل المؤسسات الرياضية بمحافظة الوادي الجديد وهي القدرة على النقاش والحوار رغم حصولها على نسبة عالية (9 . . ـ1\%).

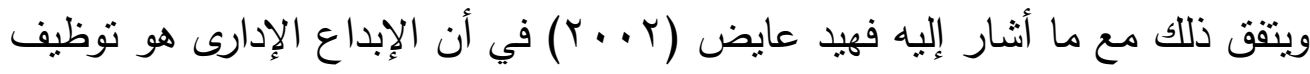
أمنل للقدرات العقلية والفكرية التى تتميز بأكبر قدر من الطلاقة والمرونة والأصالة والحساسية للمشكلات والقدرة على تحليلها بما يؤدى إلى تكوين ترابطات واكتشاف علاقات أو أفكار أو أساليب عمل جديدة داخل المنظمات الإدارية (ع 9: ^1 (1). أن الوزن النسبي لفقرات المحور الثالث الاتصال الإداري لاستبيان المتغيرات

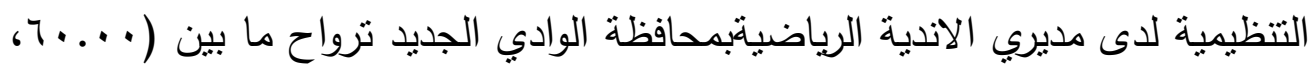




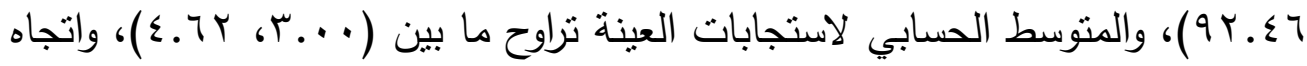
العبارات قوي.

كما يتضح أن أعلى نسبة مئوية لاستجابة عينة البحث كانت المفردة "توافر وسائل

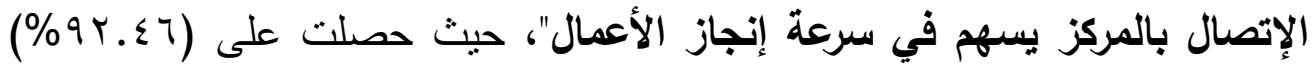
بينما حصلت المفردة "تثوافر في مركز الثباب وسائل الاتصال الفعال المختلفة" على لئ أقل نسبة مئوية بلغت (•7\%) ويرى الباحث أن الاتصال الإداري أحد أهم مكونات العملية الإدارية داخل المؤسسات بصفة عامة والرياضية بصفة خاصة، فهي تعتبر القاسم المشترك بين جميع العمليات الإدارية، فبدون الإتصال لا تتم العملية الإدارية من تخطيط وتتظم وتوجيه ورقابة. فنجد مثلاً أن قنوات الاتصال والتي يتم عن طريقها نقل المعلومات والبيانات وكذلك ودهابه نوعية المعلومات وكميتها وأيضاً الاتصالات المباشرة بين الرئيس والمرؤوسين في في لاني مناقتنة أمور العمل تؤثز على تنمية قدرات العاملين على التفكير والإبداع.

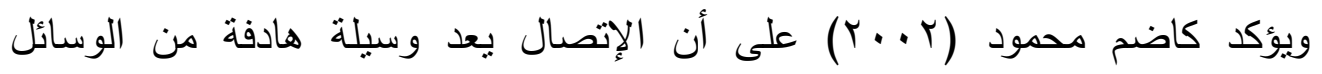
الرئيسية التي تستخدمها المنظمة في تحقيق أهدافها إذ أن كافة الأفراد العاملين في

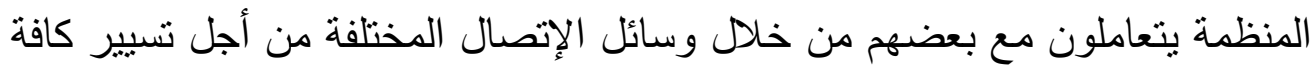

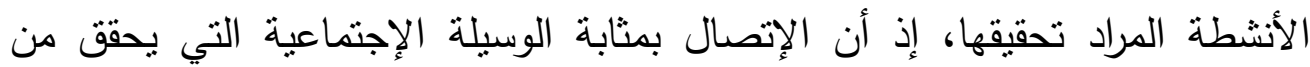
خلالها الأفر اد سبل التفاهم والتفاعل البناء في إطار تحقيق الأهداف المبتغى إنجازها.

(1) $17: 91)$

أن الوزن النسبي لفقرات المحور الرابع الإدارة الإلكترونية لاستبيان المتغيرات

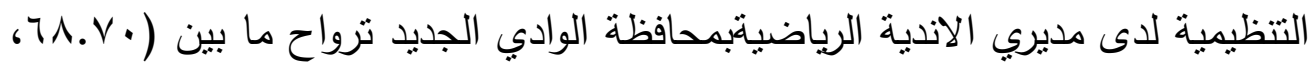

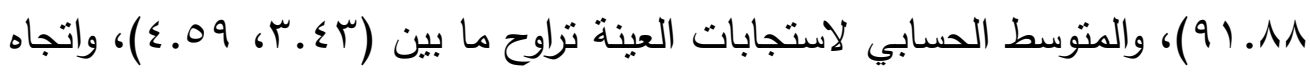
العبارات قوي. كما يتضح أن أعلى نسبة مئوية لاستجابة عينة البحث كانت المفردة "استخدام التكنولوجيا في الإدارة يساعد مجلس الإدارة على حسن استخدام موارد مركز لشباب 
بفاعلية وكفاءة اقتصادية"، والمفردة "الإدارة الإلكترونية تساعد مجلس الإدارة على

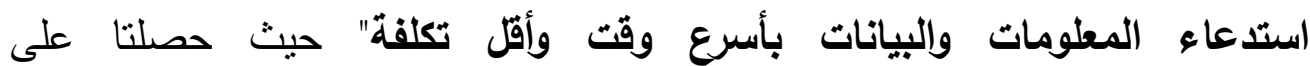
(1\%) بينما المفردة "يوفر مجلس الإدارة دورات تدريبية لتأهيل العاملين بمركز الشباب على استخدام التكنولوجيا"، والمفردة "يعمل مجلس الإدارة على استخدام التكنولوجيا في تفعيل الدور الرقابي له على الأداء الإداري بمركز الشباب" حيث حصلتا على أقل نسبة مئوية بلغت (•Y.V.V\%) ويرى الباحث أن العملية الإدارية اختلفت في العصر الحالي بعد دخول التكنولوجيا ووسائل الإتصال الحديثة وأصبحت الته أسهل وأوفر في الوقت والجهد. فإن الادارة الاككترونية تقوم بشكل أساسي على توظيف الحواسيب والتكنولوجيا في الأعمال الادارية وتحويلها من النمط التقليدي اليدوي إلى المؤتمت باستخدام الحواسيب، لهابل

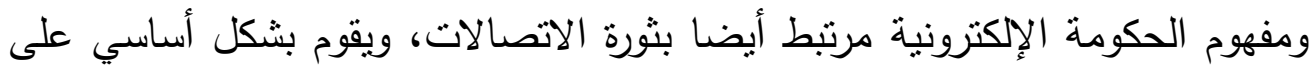

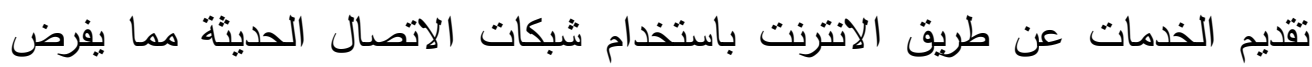
أسلوب تعامل جديد بين المواطنين وموظفي الحكومة كما يؤثر على تبادل المعلومات بين المؤسسات الحكومية. حيث يعتمد مبدأ الحكومة الإكترونية على الربط بين المؤسسات الحكومية من جهة والمؤسسات والثركات والمواطن من جهة أخرى، وذلك لك من خلال استخدام تقنيات المعلومات والاتصال. ويتفق ذلك مع ما أثنار إليه سعد غالب ياسين (0 . . ب) في أن التطور السريع لتقنية المعلومات والإتصالات أدى إلى بروز نموذج ونمط جديد من الإدارة في ظل التتافس لها والتحدي المنزايد أمام الإدارات البيروقراطية، كي تحسن من مستوى أعمالها، وجودة

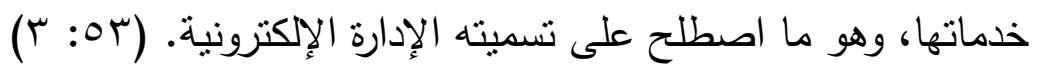
أن الوزن النسبي لفقرات المحور الخامس الهيكل التنظيمي لاستبيان المتغيرات

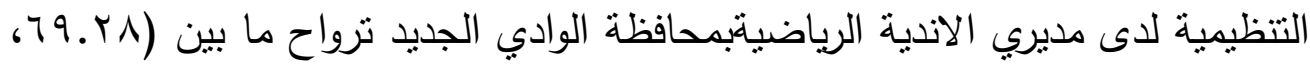

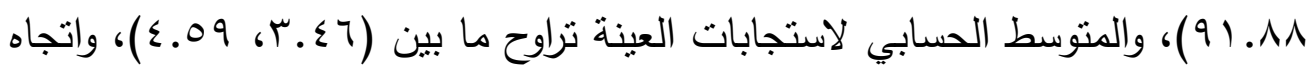
العبارات قوي. 
كما يتضح أن أعلى نسبة مئوية لاستجابة عينة البحث كانت المفردة "يجب أن يوضح الاليل التظيمي اختصاصات الوظائف بشكل واضح وقاطع"، حيث حصلت على إنى

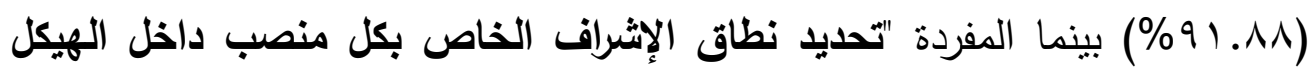
التنظيمي للوحدات الإدارة للمركز"، حيث حصلت على أقل نسبة مئوية بلغت

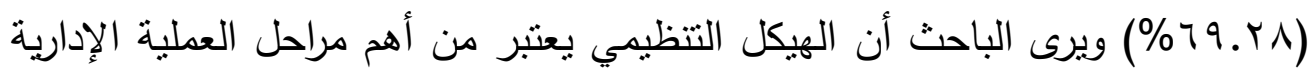
ومكوناتها فهي تحدد الإختصاصات والمسئوليات بما يضمن تحقيق العملية الإدارية لأهدافها داخل المنظمة أو الهيئة.

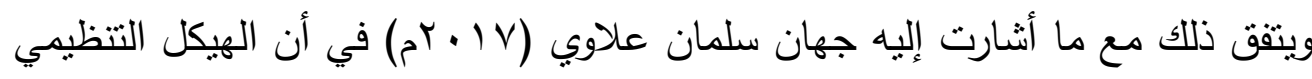
يلعب دور حيوي في إدراك المنظمة وبلوغها غاياتها وأهدافها بكفاءة وفاعلية وتكمن

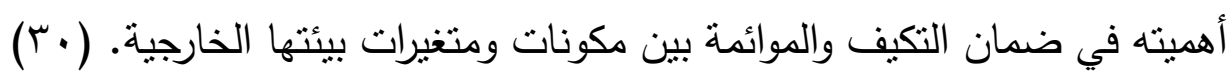
فالهيكل التتظيمي يقلل الغموض للموظف ويساعد على التفسير والتتبأ بالسلوك، فأساس الهيكل التتظيمي هو الموائمة بين غرض المنظمة والموارد اللازمة. والمنظمات التي تتمو بسرعة هي التي تستخدم الموارد استخداماً أفضل بما في ذلك ادارة الكوادر

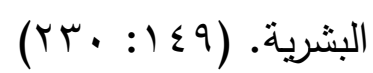

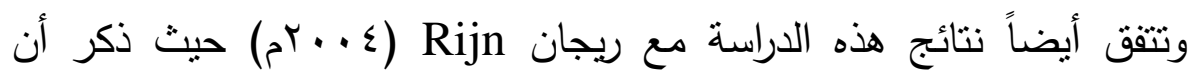

الهيكل التتظيمي يسهل العمليات المختلفة في الثركة، فالقاعدة العامة هو أن الهيكل التتظيمي يجب أن يعمل على تطوير العمليات وليس توقف التطور للعمليات المهمة

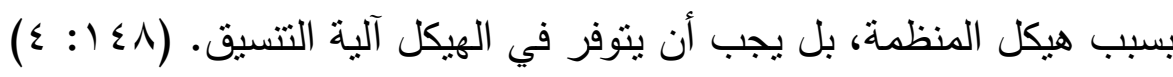

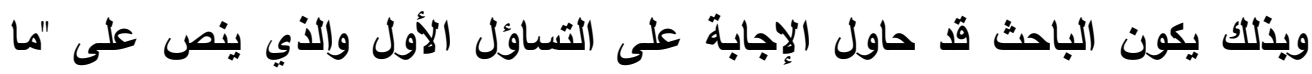
المتغيرات التنظيمية المتوفرة بالاندية الرياضيةبمحافظة الوادي الجديد؟" الإهي الهاول

نتائج التساؤل الثاني: ما مستوى جودة الأداء الوظيفي لاى مديري الاندية الرياضيتبمحافظة الوادي الجديد؟ 
أن الوزن النسبي لفقرات المحور الأول جوانب الجودة داخل داخل الهيئات الثبابية والرياضية لاستبيان جودة الأداء الوظيفي لدى مديري الاندية الرياضيةبمحافظة الوادي

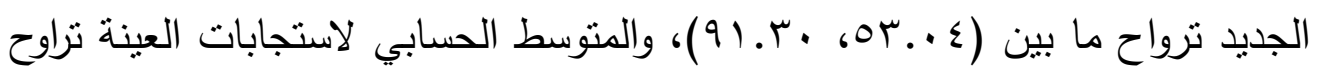

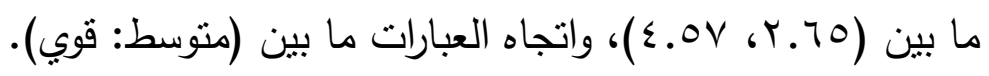

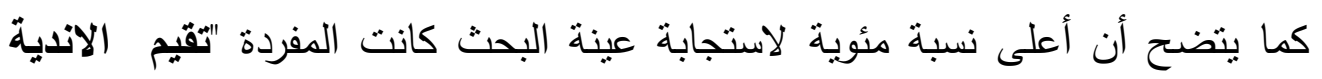

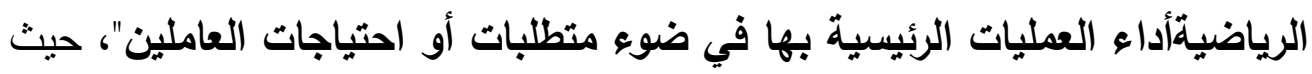
حصلت على (•r.|(\%\%) بينما المفردة "يتم تصميم البرامج المختلفة بإتباع إجراء رسمي محددة بدقة"، حيث حصلت على أقل نسبة مئوية بلغت (ع . .به\%) وقد يكون ذللك من وجهه نظر الباحث بسبب حث الإدارة العليا على تدريب العاملين على برامج

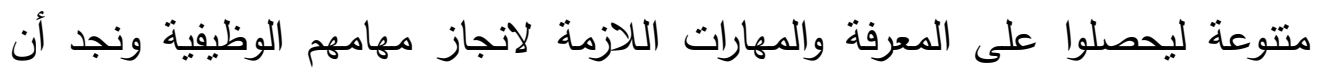
العاملين في الاندية الرياضيةيبذلوا جهدا لوضع أهدافاً شاملة تتسم بالوضوح للحصول على متطلباتهم وإجنياجاتهم. وهذا يتفق مع نتائج دراسة عمرو محمد عواد (9 9 (1))( •9) حيث أثنار إلى أن هنالك عشرة أبعاد للأداء تؤثز في جوانب جودة الأداء حيث تثتنل في كمية الأداء وجودة العمل ودرجة الثقة أو الاعتمادية على الفرد والقدرة على الانسجام مع الآخرين والعناية

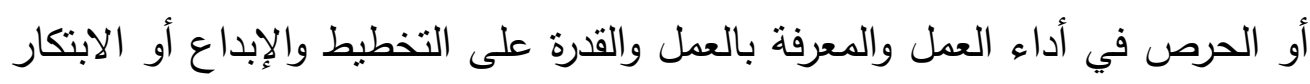

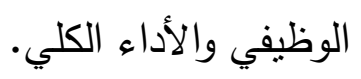

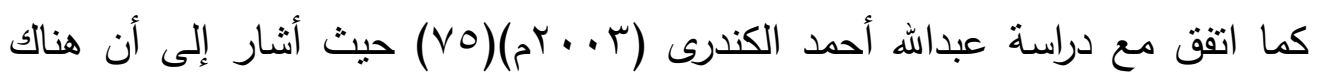

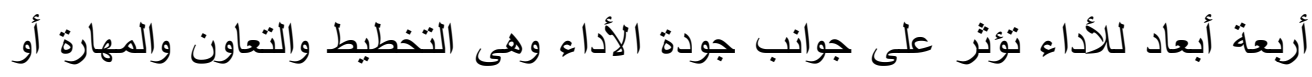

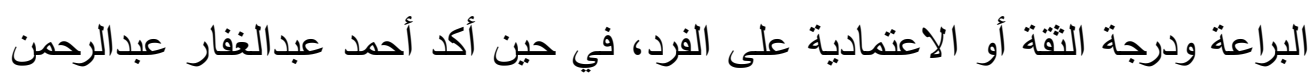

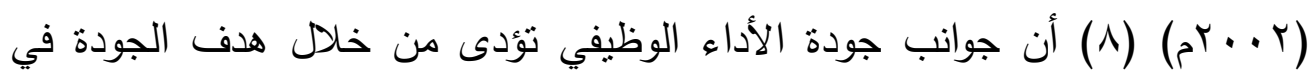
إنتاج منتجات نتبع احتباجات ورغبات العملاء. أن الوزن النسبي لفقرات المحور الثاني رضا العاملين عن الوظيفة لاستبيان جودة الأداء الوظيفي لدى مديري الاندية الرياضيةبمحافظة الوادي الجديد ترواح ما بين 


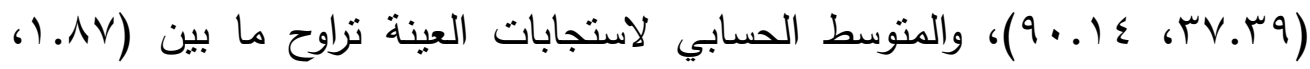

$$
\text { (0. §. )، واتجاه العبارات تراوح من (ضعيف: قوي). }
$$

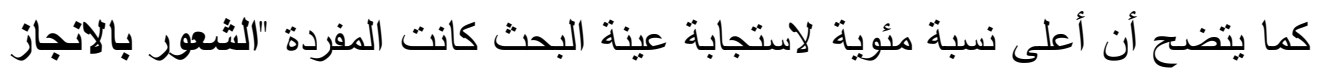
عندما تؤدى وظيفتك"، حيث حصلت على (ع ( . 9\%) بينما المفردة "تناسب العائد المادي والمزايا الإضافية التي تحصل عليها مع الجها الأي تبذله في أداء وظيفتك"،

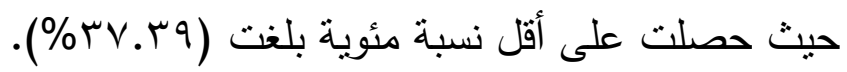

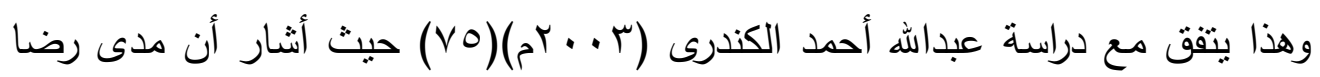
العاملين يرتبط بشكل جوهري بالعدالة التظظيمية داخل المنظمة ككل كما يتفق مع دراسة كلا من فؤاد فايد الرشيدي (T . . F م)(90) ودراسة محمد الريس العامري

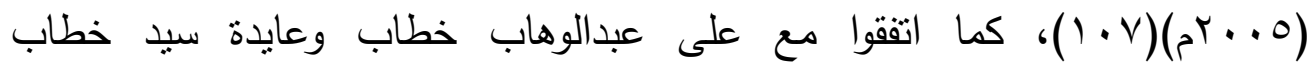

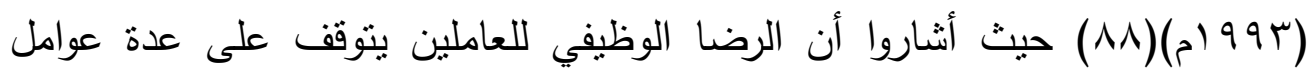
يجب أن يتبعها العامل في المؤسسة وهى العمل الذي يقوم الفرد بأدائه ومدى فهمه له، سلوك العامل في وظيفته، سلوك العامل مع زملائه في العمل ورؤسائه، طرق التحسين والتطوير التي يمكن للعامل أن يؤديها في عمله ليزيد من كفاءة ادائة الوظيفي، الحالة

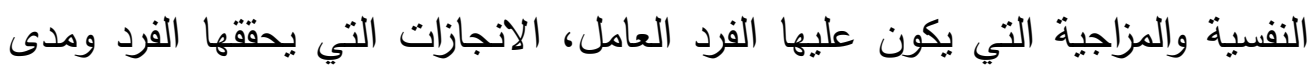

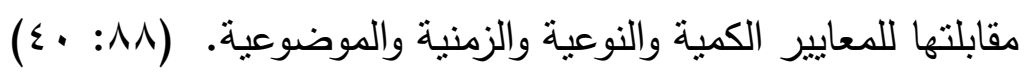
أن الوزن النسبي لفقرات المحور الثالث تقييم الأداء داخل الهيئات الثبابية والرياضية لاسنبيان جودة الأداء الوظيفي لدى مديري الاندية الرياضيةبمحافظة الوادي

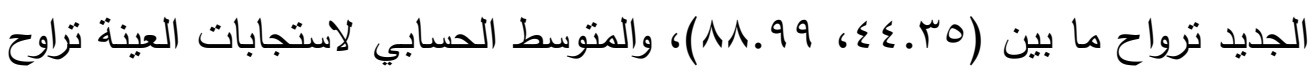

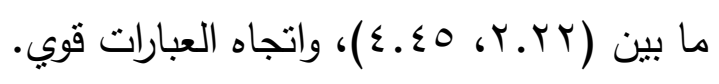
كما يتضح أن أعلى نسبة مئوية لاستجابة عينة البحث كانت المفردة "يحسن العاملين فى الاندية الرياضية/لتصرف في المشاكل التي تطرأ فجأة أثناء العمل"، حيث حصلت لته

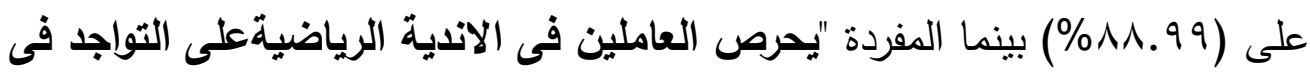
مواعيد العمل الرسمية"، حيث حصلت على أقل نسبة مئوية بلغت (0س. ؟ ؛ \%). 
وهذا ما يؤكده جاي ديسلر (0. . ب م) أنه يمكن تقيم مديري الإدارات الوسطى من خلال نموذج قياس الأداء البشرى حيث أن هذا النموذج يربط بين ما يفعله العاملين في أي منظمة وبين إستراتيجيتها كما يسمح بالمشاركة الايجابية في تحقيق الأهداف

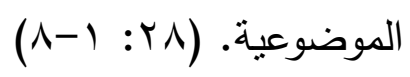

وهذا يتفق مع ما يقابله مديري الإدارات الوسطى من مشاكل أثناء عملية تقويم الأداء

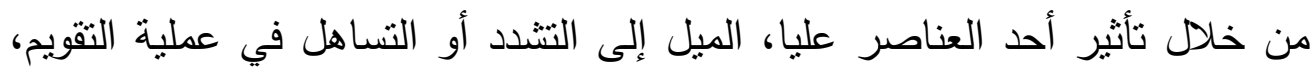
العلاقات الثخصية المتداخلة، التأثيرات التنظيمية. أن الوزن النسبي لفقرات المحور الرابع معايير جودة الاداء لاستبيان جودة الأداء الوظيفي لاى مديري الاندية الرياضينةبحافظة الوادي الجديد ترواح ما بين ( .... 7،

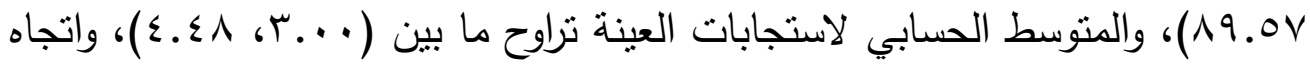
العبارات قوي. كما يتضح أن أعلى نسبة مئوية لاستجابة عينة البحث كانت المفردة "تساعد الاندية

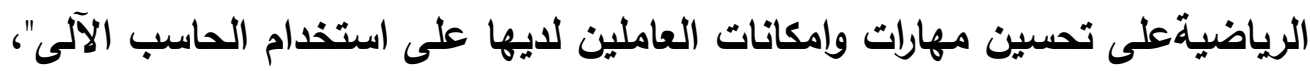
حيث حصلت على (9 (1^.9\%) بينما المفردة "يتم اتخاذ القرارات داخل الاندية الرياضيةبناء على الحقائق والبيانات ويتوافر نظام للمعلومات يساعد على ذلك"،

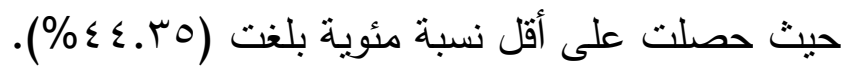

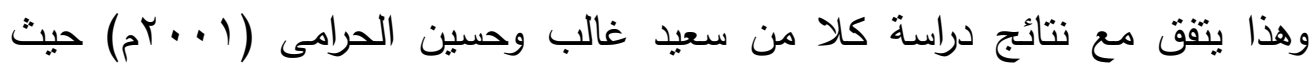
أثناروا إلى أنه يوجد اختلاف في الأهمية النسبية التي يوليها المديرين لمعايير جودة المعلومات الفندقية حيث توجد فروق ذات دلالة إحصائية في الأهمية النسبية يوليها المديرين لمعايير قياس جودة المعلومات الفندقية. (7ه) 


\section{جدول (1)}

القيم التائية المحسوية لالالة الفرق بين الوسط الحسابي والوسط الفرضي لمفردات استبيان جودة الأداء الوظيفي لدى مديري الاندية الرياضيةبمحافظة الوادي الجديا

\begin{tabular}{|c|c|c|c|c|c|}
\hline \multicolumn{6}{|c|}{$(1 \mu=\dot{U})$} \\
\hline درجة & القيمة التائية & القيمة التائية & الوسط & الاتحراف & المتوسط الحسابي \\
\hline حرية & الجدولية & المحسوية & الفرضي & المعياري & للعينة \\
\hline 71 & 1.91 & 1.71 & TTE & $91 . Y \leq$ & $r \leqslant 0.01$ \\
\hline
\end{tabular}

يتضح من جدول (1) وجود فروق غير دالة إحصائيا بين المتوسط الحسابي للعينة والوسط الفرضي في جودة الأداء الوظيفي لدى مديري الاندية الرياضيةبمحافظة الوادي

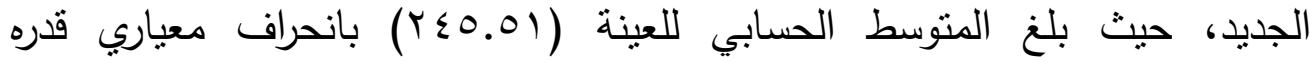
(צ.Y.(9)، كما بلغ الوسط الفرضي (ع Y)، كما بلغت القيمة التائية المحسوبة (11. (1) وهي أصغر من القيمة التائية الجدولية عند مستوى دلالة (0. ..). ويرى الباحث أن هذه النتيجة تثير إلى أن الاندية الرياضيةبمحافظة الوادي الجديد بصفة عامة تقتقر إلى الجودة في الأداء الوظيفي وقد يكون ذلك بسبب ضعف الإمكانات المادية والبشرية داخل المراكز وقد يكون أيضاً بسبب عدم توافر أسلوب رقابة فعال وعدم وجود معايير تقييم تحدد مدى جودة البيئة الإدارية داخل الهيئة. فجودة الأداء الوظيفي هي مجموعة من السلوكيات التي تعبر عن قيام الفرد بعطله بشكل مميز، ويتضمن جودة الأداء، وحسن التتفيذ، والخبرة الفنية، والإبداع، والإلتزام باللوائح والقوانين الخاصة بالعمل، وأخيرا الاتصال والقدرة على التفاعل مع الآخرين داخل المنظمة.

ويذلك يكون الباحث قد حاول الإجابة على التساؤل الثاني والذي ينص على "ما مستوى جودة الأداء الوظيفي لدى مديري الاندية الرياضيتبمحافظة الوادي الجديد؟"

التساؤل الثالث: هل توجد علاقة دالة إحصائية بين المتغيرات التنظيمية (قيل البحث) وجودة الأداء الوظيفي لدى مديري الاندية الرياضيةبمحافظة الوادي الجديد؟ 


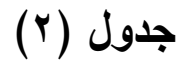

معامل الإرتباط بين المتغيرات التنظيمية (قيد البحث)

وجودة الأداء الوظيفي لاى مديري الاندية الرياضيةبمحافظة الوادي الجديد (ن ب ا )

\begin{tabular}{|c|c|c|c|c|}
\hline قالمحسة ر & الانعياري & الحسابي & ال المتغير & s \\
\hline \multirow{2}{*}{$\because 9 \mathrm{~V}$} & $91 . Y \leq$ & $r \leqslant 0.01$ & المتغيرات التنظيمية. & 1 \\
\hline & $\wedge 9 \ldots$ & $r v \cdot . \leqslant r$ & جودة الأداء الوظيفي. & $r$ \\
\hline
\end{tabular}

يتضح من جدول (r) أن هنالك علاقة دالة إحصائياً بين المتغيرات التنظيمية وجودة

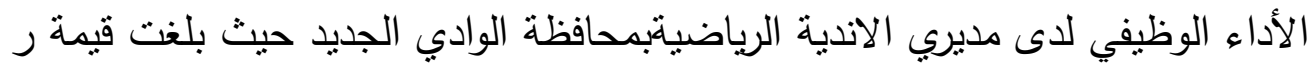

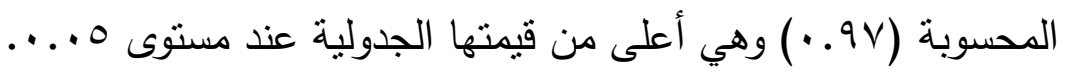
ويرى الباحث أن هذه النتيجة منطقية حيث أن جودة الأداء الوظيفي لا تأني إلا من خلال بيئة تتمتع بمجموعة من المتغيرات التنظيمية التي تضمن بيئة إدارية جيدة

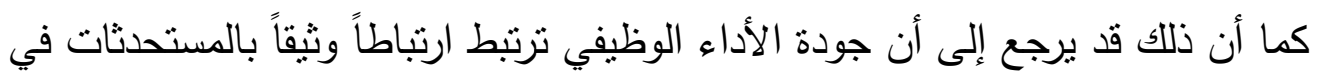

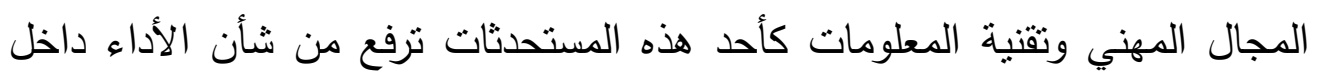
المنظمات. أي أنه كلما كانت البيئة الإدارية تتمتع بمتغيرات تتظيمية جيدة كلما ارتفع مستوى جودة

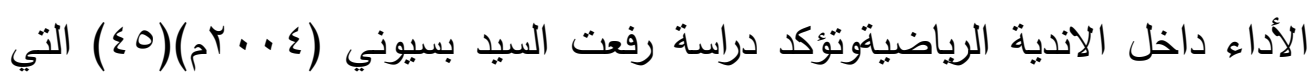
أثارت إلى أن عدم وجود نظام معلومات (كأحد مخرجات الإدارة الإلكترونية) يعتمد على الحاسب الآلى لإدارة شئون العاملين يؤدى ذلك إلى الخى إنىاض مستوى كفاءة الأداء

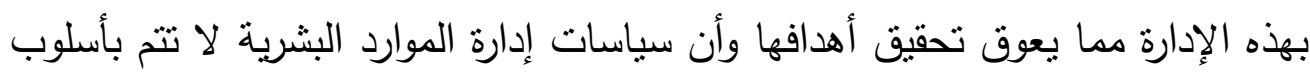
علمي سليم. وبذلك يكون الباحث قد حاول الإجابة على التساؤل الثالث والذي ينص على "هل توجد علاقة دالة إحصائية بين المتغيرات التنظيمية (قيد البحث) وجودة الأداء الوظيفي لاى مديري الاندية الرياضيةبمحافظة الوادي الجديد؟" لهين" 
التساؤل الرابع: ما نسبة مساهمة المتغيرات التنظيمية على جودة الأداء الوظيفي لاى مديري الاندية الرياضيةتبمافظة الوادي الجديد؟ جدول (r)

معاملات الإنحدار بإستخدام الخطوة المتدرجة إلى الأمام Stepwise مع المتغيرات التظظيمية وجودة الأداء الوظيفي لاى مديري الاندية الرياضيةبمحافظة الوادي الجديا الإمام $(1+\dot{r}=\dot{0})$

\begin{tabular}{|c|c|c|c|c|c|c|c|c|}
\hline مستوى & قيمة ت & 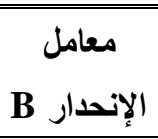 & مستوى & قيمة ف & المساهمة & الإرتباط & المستفيرة & المتغير التابع \\
\hline$\ldots$ & r4.17 & .90 & $\ldots$ & $r \cdot v . v q$ & .90 &. $.9 V$ & التنظيمية & جودة الأداء \\
\hline
\end{tabular}

يتضح من جدول (r) أن المتغيرات التنظيمية تؤثر على جودة الأداء الوظيفي ، حيث

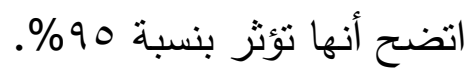

ويرى الباحث أن هذه النتيجة طبيعية ومنطقية فجودة الأداء الوظيفي تنأثز بالمتغيرات التنظيمية فكلما تحسنت المتغيرات التنظيمية كلما كان هناك جودة في الأداء

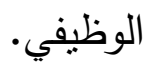

فجودة حياة العمل تعد من المفاهيم الادارية التي تشير إلى الظروف البيئية

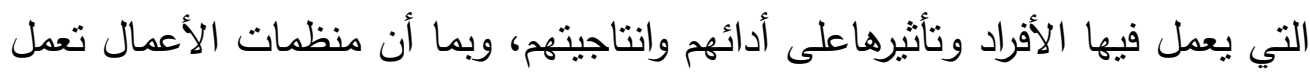
في بيئة شديدة المنافسة ولكي تتمكن من زيادة قابليتها أو قدرتها على المنافسة فإنها تركز على الاهتمام بالموارد البشرية المتوفرة لديها لتدفعهم لبذل جهود إضافية لتحقيق الأهداف التنظيمية.

وتتفق هذه النتيجة مع ما أثنارت إليه كل من نفرين عارف حجي، شلير عبدالرحمن علي محمد (9 ( • r) في أن قدرة المنظمة ترتبط على البقاء والاستمرار بممارسة نشاطاتها وقدرتها على التكيف مع التغييرات التي تحدث في بيئتها الداخلية والخارجية على حد سواء، وتشمل البيئة الداخلية للمنظمة على العديد من العوامل 
المتداخلة والمتشابكة، والتي تؤثر بمجملها على نوعية حباة العمل، ونظراً لأن المورد

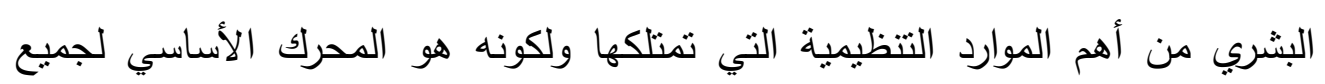
الموارد التتظيمية الأخرى (المادية والمالية والمعلوماتية) ولغرض الاستفادة القصوى من هن

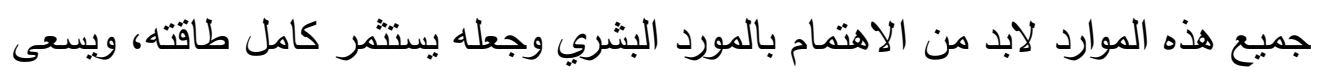

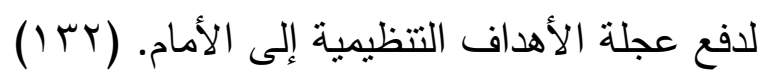

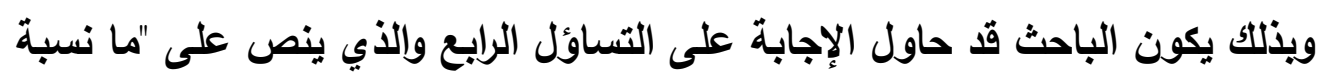
مساهمة المتغيرات التنظيمية على جودة الأداء الوظيفي لاى مديري الاندية الرياضيةبمحافظة الوادي الجديد؟"

التساؤل الخامس: ما التصور المقترح لجودة الأداء الوظيفي لاى مديري الاندية الرياضيةبمحافظة الوادي الجديد في ضوء بعض المتغيرات التنظيمية؟ تم التوصل إلى التصور المقترح

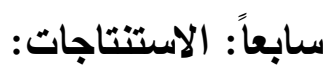

في ضوء أهداف البحث وتساؤلاته وفي حدود العينة والمنهج المستخدم والمعالجات الإحصائية والنتائج التي توصل إليها الباحث أمكن التوصل إلى وفئىلى الاستتناجات التالية:

\section{استنتاجات التساؤل الأول: الأه}

1- المتغير التظظيمي الإبداع الإداري حصل على الترتيب الأول بنسبة مئوية

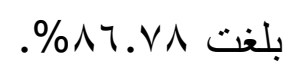

r- المتغير التظظيمي الاتصال الإداري حصل على الترتيب الثاني بنسبة مئوية

$$
\text { \% بلغت }
$$

ب- المتغير التظيمي الهيكل التنظيمي حصل على الترتيب الثالث بنسبة مئوية

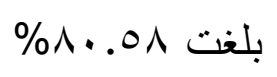


ع- المتغير التنظيمي الثقافة التنظيمية حصل على الترتيب الرابع بنسبة مئوية

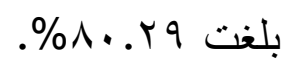

0- المتغير التظظيمي الإدارة الإلكترونية حصل على الترتيب الخامس بنسبة مئوية

$$
\text { بلغت }
$$

צ- اتجاه عبارات استبيان المتغيرات التتظيمية تراوح بين الاتجاه المتوسط والقوي.

$$
\text { استنتاجات التساؤل الثاني: }
$$

1- حصل المحور الرابع معايير جودة الأداء على التزتيب الأول بنسبة مئوية بلغت

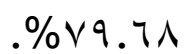

ץ- حصل المحور الأول جوانب الجودة داخل المؤسسات الثبابية والرياضية على

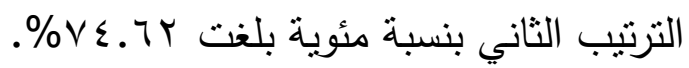

ץ- حصل المحور الثالث تقييم الأداء داخل المؤسسات الثبابية والرياضية على

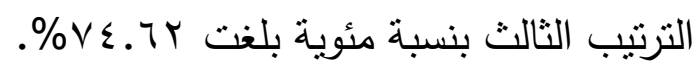

ع - حصل المحور الثاني رضا العاملين عن الوظيفة على الترتيب الرابع بنسبة مئوية

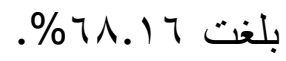

0- اتجاه عبارات استبيان جودة الأداء الوظيفي تراوح بين الاتجاه الضعيف والقوي. 7-وجود فروق دالة إحصائياً في مستوى جودة الأداء الوظيفي بالنسبة للوسط

$$
\text { الفرض. }
$$

استتناجات التساؤل الثالث:

1-وجود علاقة غير دالة إحصائياً بين المتغيرات التتظيمية وجودة الأداء الوظيفي.

استنتاجات التساؤل الرابع: 1- المتغيرات التتظيمية تساهم بنسبة 90\% في جودة الأداء الوظيفي. 
استتناجات التساؤل الخامس:

ا- تم التوصل إلى التصور المقترح لجودة الأداء الوظيفي لدى مديري الاندية الرياضيةبمحافظة الوادي الجديد في ضوء بعض المتغيرات التتظيمية

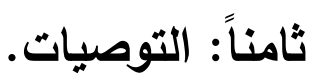

في ضوء ما أظهرته نتائج هذه الدراسة يوصي الباحث بالتوصيات التالية: 1-ضرورة الاهتمام بالتقافة التنظيمية لدى مديري الاندية الرياضيةبمحافظة الوادي الجديد.

r-ضرورة الاهتمام بالابداع الإداري لدى مديري الاندية الرياضيةبمحافظة الوادي الجديد.

r- ضرورة الاهتمام بالادارة الإلكترونية بالاندية الرياضيةبمحافظة الوادي الجديد. ع - ضرورة الاهتمام بالاتصال الإداري بالاندية الرياضيتبمحافظة الوادي الجديد. 0- ضرورة الاهنمام بالهيكل التنظيمي بالاندية الرياضيتبمحافظة الوادي الجديد 7- إجراء العديد من الدراسات التي تهنت بمتغيرات تتظيمية أخرى ومعرفة تأثيرها على

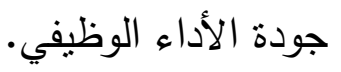

V- بناء برامج تدريبية لمديري الاندية الرياضيةفي الحديث في المجال الإداري. 1- إجراء دراسة مشابهة لفئات وظيفية أخرى تضم جوانب الدراسة الحالية. 9- العمل دائماً على تحسين جودة الأداء الوظيفي لدى العاملين بالهيئات الرياضية والثبابية. 


\section{المراجع}

ا- إبراهيم سلطان: نظم المعلومات الإدارية (مدخل النظم)، الدار الجامعية، مصر،

$$
\cdot 0 r \cdot 0
$$

ץ- إبراهيم عثمان: مقدمة في علم الاجتماع، دار الثروق للنشر والتوزيع، عمان،

$$
\text { 6r. }
$$

ب- أبو بكر محمد يوسف: إطار مقترح لدور الثقافة التظظيمية فى تطبيق الأساليب لخفض التكلفة، المجلة العلمية، كلية التجارة، جامعة الزقازيق، ؟ +. rم. ع- أحمد السيد مصطفى: إدارة الموارد البشرية منظور القرن الحادي والعشرون،

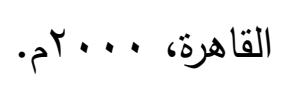

ه- أحمد السيد مصطفى: إدارة الموارد البشرية، روئية إستراتيجية معاصرة، دار الفكر

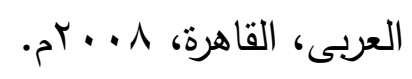

1- نظام ضبط ومراقبة جودة الإنتاج في قطاع الصناعات الغذائية، رسالة دكتوراه، أحمد بري: تطبيقات الإدارة الاككترونية في العمليات المنظومة، دار المعارف،

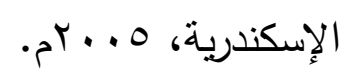

V- أحمد سعد غالب ياسين: أساسيات نظم المعلومات الإدارية وتكنولوجيا

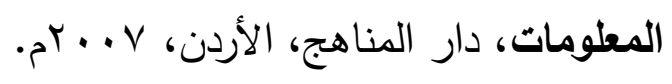


ᄉ- أحمد عبدالخالق العوضى: أثر الحكومة الإكترونية على الجودة الشاملة والأداء الوظيفي، دراسة تطبيقيه على الاوائر المحلية بحكومة دبي، رسالة ماجستير،

$$
\text { كليه التجاره، جامعه عين شمس، } 1 \text {. . بام. }
$$

9- أحمد عبدالغفار: تقويم المعهد القومي للإدارة العليا، أكاديمية السادات للعلوم

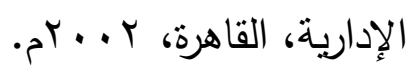

أحمد عزمي إمام: تأثير برنامج تنمية بشرية مقترح على الإبداع الإداري لاي طلاب كلية التربية الرياضية، رسالة دكتوراه، كلية التربية الرياضية، جامعة المنيا، I1 ـ بع.

10- Al-Kharusi, B., Aldhafri, S., Al-Kharusi, H., AlBusaidi, S., Ambosaidi, A., Al-Hosani, K., \& Alrajhi, M.: Measuring the quality of working life of teachers: Theoretical models and results of exploratory factor analysis. A paper presented at the 4th International Conference of the College of Education, Muscat, Sultanate of Oman, 2016.

11- Bemett.T: Anew Vision Of Performance Evolution

Process: Afield Study and laboratory Experiment "Organizational V.59, 2000.

12- Brynjolfsson E. \& Yang S.: Information Technology Productivity A review of the literature advances in computers, Academic press, Cambridge, Volume 43, P 50, 1996

13- Cengiz Yilmaz: Sales Person Performance and job attitudes Revisited: An extended model and effects of 
potentid Moderators European Journal of Marketing; volume: 36 issue: 11/1, 2002

Chang, Tsung- Ling: Six Sigma A Framework for small and Medium-Sized Enterprises to Achieve Total Quality Unpublished Ph.D. Thesis U.S.A -Ohio Cleveland State University, 2005 